\title{
Closing and Opening Triangles
}

from our Biological Chemistry Correspondent<smiles>CC(C)=CCC/C(C)=C/CC/C(C)=C/CC/C=C(\C)CC/C=C(\C)CCC=C(C)C</smiles><smiles>[Y6]/C(=C\C1C(C)C1(CO)CC/C=C(\C)CCC=C(C)C)CC/C=C(\C)CCC=C(C)C</smiles>

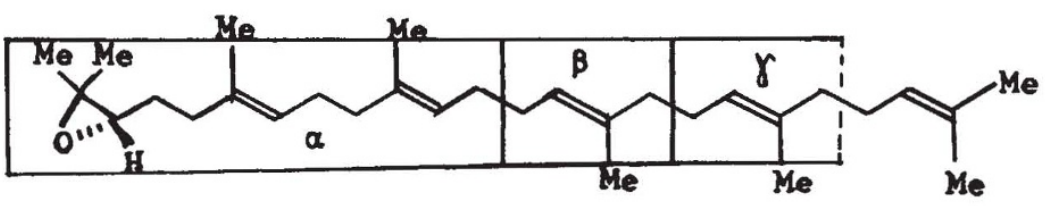

(III)

CORNFORTH and Popják's classical studies of the route by which mevalonic acid is converted into squalene and thence into sterols provided stereochemical detail which was little short of amazing at the time but left unsolved the problem of just how two C-15 farnesyl residues are united, tailto-tail, to give squalene (I). The enzyme responsible, squalene synthetase, proved difficult to manipulate, but two research groups eventually culled from its grasp similar, possibly identical, presqualene alcohols in the form of pyrophosphate esters. Provisional structures were proposed by Rilling and by Popják for their C-30 intermediates though Rilling's failed to survive the test of a Corey synthesis and Popják's awaits such trial.

Rilling thereupon revised the structure of his cyclopropanecarbinol to (II) and Crombie has now achieved a neat synthesis of this material (J. Chem. Soc. D., 218; 1971). Although the methods used gave all four diastereoisomeric racemates, these proved separable by the combination of gas-liquid and thin-layer chromatography. Just one of the mixtures of enantiomers had spectra identical with Rilling's precursor and could be converted into squalene by a yeast microsomal preparation with fair efficiency.

If (II) is really a true intermediate in the biosynthesis of squalene, the formation and subsequent destruction of a cyclopropane ring must surely be one of nature's most devious methods for making a single carbon-carbon bond.

In contrast, recent progress in van Tamelen's group at Stanford University (J. Amer. Chem. Soc., 92, 7202, 7204, $7206 ; 1970)$ shows that the further
ORBITALS

In Honour of Coulson

from a Correspondent

Professor Charles Coulson's sixtieth birthday conference in Oxford on April 1 and 2 provided his many friends and pupils with a very welcome opportunity to express their affection and gratitude. The conference was generally concerned with orbitals in atoms, molecules and crystals, as was very proper to honour the founder of quantum chemistry, but covered a wider field, from density matrices to the properties of the analogues of vitamin $B_{12}$ (Dr M. Green, University of York).

One session of particular interest concerned the possible killing off of orbitals, to be replaced by density matrices. Professor E. Bright Wilson (Harvard University) pointed out the difficulties caused by the fact that the second order density matrix must obey an extraordinarily large number of necessary conditions, and he was pessimistic over the chances of ever constructing it. Professor A. J. Coleman (Queen's University, Ontario) brought a ray of hope, based on abstract set theory, but Professor Coulson and Professor N. H. March (University of Sheffield) were more optimistic and suggested that perhaps all the conditions will turn out to be satisfied automatically, or may not be so important. Related to this was the lecture by Professor March who described his group's important work towards the solution of the many-body problem.

\section{Hope of Sufer Human Marrow Grafis}

A NOVEL technique which may eventually prove of value in the development of human marrow grafting is reported in next Wednesday's Nature New Biology. L. J. Cole and S. E. Maki of the Stanford Research Institute, California, have devised a way to overcome the chief obstacle to the widespread use of bone marrow grafting in the treatment of leukaemia and immunological deficiency diseases. This obstacle is the development of graft versus host $(\mathrm{GVH})$ disease which swiftly follows transplantation, and which is the result of the immunological reaction between the cells of the donor graft and the tissue antigens of the host.

Cole and Maki have inactivated the cells in the donor marrow which are responsible for initiating the lethal GVH response, by treating them with heterologous anti-mouse $\gamma$-globulin serum. The efficacy of this method hinges on the fact that the immunologically active marrow donor cells--the lymphocytescarry on their surface immunoglobulin- like molecules which can combine with antigen in which the active sites are of complementary configuration. Coles and Maki therefore treated mouse antigenreactive lymphocytes with either normal rabbit serum (NRS) or anti-mouse 7S $\gamma$-globulin serum. Theoretically, the anti-mouse serum should bind to the reactive sites on the surface of the lymphocytes so rendering them immunologically inactive, and indeed Coles and Maki found that sub-lethally irradiated mice injected with the anti-mouse serum neither died nor showed signs of runting disease. In contrast, all the mice injected with NRS showed signs of runting and eventually died. Further experiments in which allogeneic bone marrow cells were treated with the heterologous anti-mouse serum were equally encouraging, especially because the serum does not seem to interfere with the ability of bone marrow stem cells to form haemopoietic colonies, a critical feature in the repopulation of haemopoietic tissues. 